\title{
Population Change in the United Kingdom
}

\author{
edited by Tony Champion and Jane Falkingham \\ London and New York: Rowman and Littlefield, 2016 \\ ISBN 978-1-78348-592-5 \\ Softcover, US\$44.95, 275 pp.
}

\section{Reviewed by Barry Edmonston \\ University of Victoria}

Books studying the demography of national populations have some interesting features. Most books of this type are published on the occasion of a recent population census. In Canada and the United States, for example, "census volumes" were published after censuses from the 1930s to the 1990s. These volumes provided useful discussions of population changes because official census statistics were lengthy, detailed, and often complicated tabulations. Earlier census tabulations were printed in large collections that were generally available only in larger libraries. In order to interpret population changes for the general public, census volumes were usually authored by leading population scholars familiar with specialized topics, such as population change or internal migration.

In recent years, census data and reports have become widely available on the internet, and have largely replaced the need for census volumes. Nevertheless, occasional books are published that survey a nation's population situation, such as the recent Population Change in the United Kingdom. While this book was not undertaken as a traditional census volume, it has some similarities: its chapters mainly rely on analysis of the 2011 UK census and discuss the key demographic characteristics and processes affecting the UK population.

During the 1980s, population issues were not a prominent part of British thinking about social and economic policy. In the mid-1980s, the British Society for Population Studies (BSPS) collaborated with the Centre for Economic Policy Research in the United Kingdom on a series of lectures addressing the major challenges facing society as a result of the changing demography of Britain. Professor Heather Joshi, then president of the BSPS, compiled the lectures together in a book, entitled The Changing Population of Britain, published by Blackwell Publishing in 1989. In the mid-2010s, the BSPS brought together population scholars and policymakers to update the essays in the 1989 volume, resulting in the book under review here. The purpose of the updated work was twofold: first, to highlight demographic changes during the past twenty-five years since the earlier volume and, second, to improve understanding of the determinants and consequences of current demographic change in Britain. This volume documents the analysis, conclusions, and implications for future research by leading British population scholars.

Population Change in the United Kingdom discusses most of the topics that would be expected in a traditional census volume, although there are several noticeable omissions. Population processes are covered, with chapters examining general population change, population composition, population distribution, fertility, mortality and health, international migration, and internal migration. 
The book includes the subjects of families, households, and ethnicity, but several other topics are missing. The UK census does not ask respondents about income or sources of income. Hence, there is a noteworthy absence of census results on income and poverty. British demographers have developed several census-based small-area measures as a partial replacement for low-income statistics, which are examined in Chapter 11 of Population Change in the United Kingdom. Finally, the book does not discuss educational attainment and labour force status, which seems peculiar given the importance of these two topics for current United Kingdom social and economic debate.

This edited volume includes a brief foreword and preface, and eleven chapters. Chapter 1, written by the two co-editors of the book, provides a general introduction to the volume. It also discusses population change during the past quarter-century, and Britain's expected future population changes over the next twenty-five years. As in Canada, an increasing proportion of UK population growth stems from international migration. And, similar to Canada, the population is aging and becoming more ethnically diverse. The editors point out that the $2021 \mathrm{UK}$ census will primarily use online data collection, and that later censuses are likely to rely increasingly on administrative records. There will be significant future challenges for data providers and users in order to maintain data quality and continuity of census data series.

The next two chapters examine population aging and its implications for elderly health and social care. Chapter 2 proposes that population aging is predictable, because the forces of low fertility guarantee an increasingly older population. The proportion aged 65 years and older in the United Kingdom almost doubled, from 10 per cent in 1941 to 18 per cent in 2014, and is projected to grow to 24 per cent in 2041. But it is not only the number and proportion of elderly that has implications for health and social care. Increases in the number of elderly living alone and in the proportion of elderly who are childless will reduce the potential for social care from partners and children, and place more need on public services. Chapter 3 examines the challenge of ensuring the well-being of all British elderly, not only a privileged few. Social and spatial inequalities in the health and life expectancy of older people have been stable, and may have even widened in recent years. This chapter provides a helpful summary of available evidence about inequalities in elderly health and mortality, and about future research questions that require answers.

The next two chapters, 4 and 5, concern immigration trends and immigrant fertility. Chapter 4 correctly argues that increased immigration is not a solution for population aging. But there is great uncertainty concerning anticipated future immigration levels-especially now, due to possible Brexit arrangements and changes to UK immigration rules - and about the future numbers of immigrant admissions and selection of types of immigrants. Future changes in the UK's role within Europe's custom and economic unions create additional uncertainty about how attractive the UK will be for potential immigrants. Chapter 5 provides evidence from survey data that immigrant fertility decreases with duration of UK residence, and that fertility of the descendants of immigrants is converging to national levels. Overall, decreasing fertility among the foreign-stock population points to lower future UK fertility levels.

Two chapters examine aspects of UK families and households. Chapter 6 takes a children's perspective on the dynamics of family structure. The most important trend is that family size has been decreasing in recent years. Smaller family size improves the availability of parental resources but shrinks the overall family network. Overall, as children mature into adulthood, they may rely more on friendship than family networks, even though friends are less likely than family to care for frail or older adults. Chapter 7 examines the effects of the lower level of new housing units that have been built in recent years. Fewer new units, coupled with removal of older, dilapidated housing, has created supply restrictions on the growth of available housing. This chapter offers useful reading for applied demographers, with its interesting use of methods for projecting housing units. 
The next two chapters deal with internal migration and ethnic diversity. Chapter 8 identifies three main trends in UK internal migration during the past quarter-century: (a) a reduction of geographic mobility, except for university students; (b) a fading of southward migration, which was substantial until the 1980s; and (c) a slowdown of the urban exodus, with a trend toward urban recovery. Decreases in residential mobility may be partially due to lower rates of adding new housing units, a topic examined in chapter 7. Chapter 9 discusses the overlap of international and internal migration, pointing out that the foreign-born are dispersing from their places of original settlement. The resettlement of the foreign-born alters the composition of their original ethnic communities and increases the ethnic diversity of their new destinations.

Chapter 10 deals with sexual and reproductive health (SRH), including the study of trends in sexual partnerships, contraceptive use, induced abortion, and sexually transmitted diseases. The chapter argues convincingly for the importance of monitoring and studying SRH in order to constantly adapt and improve policy, service, and data systems.

Chapter 11 concerns challenges in monitoring deprivation and social exclusion, largely because the UK census does not collect data on income or income sources. As a result, the study of the low-income population has been measured by proxy indicators, including unemployment, non-car ownership, non-house ownership, and housing overcrowding (defined as more than one person per room). However, these deprivation measures have limitations: secular trends in the indicators affect changes in overall deprivation; outcome measures are for small-areas and not available for individuals or households; and trends over time require data to have comparable geographies. Although the advantages and limitations of deprivation measures appear to be well-known to UK researchers, improvements in the study of factors affecting the low-income population will require study of longitudinal data for individuals and families.

This edited volume is an important book for the study of population changes in the United Kingdom. The eleven chapters cover a range of demographic topics that will also be of interest to Canadian and other researchers. 